\title{
Vasculopathic cranial ocular motor neuropathy following sudden emotional stress
}

\author{
Valerie Purvin ${ }^{1,2,3 *}$ \\ 1 Midwest Eye Institute, Indianapolis, IN, USA \\ 2 Department of Ophthalmology, Indiana University Medical Center, Indianapolis, IN, USA \\ ${ }^{3}$ Department of Neurology, Indiana University Medical Center, Indianapolis, IN, USA
}

\section{Edited by:}

Swaraj Bose, University of California,

Irvine, USA

\section{Reviewed by:}

Swaraj Bose, University of California, Irvine, USA

Prem Subramanian, Johns Hopkins

University School of Medicine, USA

\section{${ }^{*}$ Correspondence:}

Valerie Purvin, Midwest Eye Institute, 200 West 103rd Street, Suite 1000,

Indianapolis, IN 46290, USA.

e-mail:vpurvin@iupui.edu
We describe three patients who experienced onset of a microvascular ocular motor nerve palsy in the setting of sudden emotional stress. Such emotional states are accompanied by a marked increase in sympathetic tone in some individuals. Mechanisms by which these autonomic changes might produce an ischemic cranial nerve palsy include intra-cranial vasoconstriction and transient systemic hypotension due to alterations in cardiac function.

Keywords: cranial neuropathy, microvascular palsy, vasculopathic cranial nerve palsy

\section{INTRODUCTION}

Microvascular ischemia is the most common cause of acute, isolated diplopia in individuals over age 50 (Lapresle and Lasjaunias, 1986; Richards et al., 1992). Based on the few available post-mortem studies, the location of the lesion in these vasculopathic palsies is within the subarachnoid or intracavernous portion of the nerve (Asbury et al., 1970; Weber et al., 1970). The mechanism probably involves ischemic demyelination in the watershed area between vascular territories supplying the nerve (Cahill et al., 1996). While the majority of patients with such ischemic cranial mononeuropathies have identifiable vascular risk factors including age, diabetes mellitus, hypertension, and hyperlipidemia (Jacobson et al., 1994), in most cases no immediate precipitating event is identified. We describe three patients who experienced onset of an isolated ischemic ocular motor nerve palsy in the setting of sudden emotional stress.

\section{CASE REPORTS \\ CASE 1}

This 81-year-old diabetic minister experienced sudden onset of horizontal diplopia accompanied by a mild ache behind the left eye while walking back to the limousine at his wife's funeral service. Neuro-ophthalmic examination 2 days later revealed only $10^{\circ}$ of abduction of the left eye past midline and a 25 diopter esotropia. The general neurologic examination was otherwise normal. A complete blood count $(\mathrm{CBC})$ and erythrocyte sedimentation rate (ESR) were normal and his blood sugar was adequately controlled. A computerized tomographic scan of the head was also normal. Re-examination 1 month later showed modest improvement and 3 months later demonstrated complete resolution of his left 6th nerve palsy.

\section{CASE 2}

A 70-year-old hypertensive man had an unusually heated argument with his wife while at home. He then got into his car so that he could go somewhere to "let off steam" whereupon he experienced very brief confusion followed immediately by horizontal diplopia that persisted. Neurologic examination acutely was normal except for a left 6th nerve palsy. Neuro-ophthalmic examination 4 weeks after onset revealed a 4 diopter esotropia in primary position that increased to 14 diopters on left gaze. There was incomplete abduction of the left eye with mild slowing of left lateral rectus saccades. Other findings were normal. A magnetic resonance imaging (MRI) scan showed only small vessel disease, a CBC, and ESR were normal. He experienced progressive improvement of diplopia beginning 5 weeks after onset. On re-examination 3 months later he was orthophoric in all fields of gaze with full eye movements and brisk saccades.

\section{CASE 3}

This 57-year-old man experienced sudden onset of oblique diplopia associated with a mild left retro-orbital ache while at his mother's deathbed. He subsequently noted, in addition, drooping of the left upper lid. His past medical history included diabetes mellitus, hypertension and hypercholesterolemia. His pain resolved after a few days but other deficits persisted. Neuro-ophthalmic examination 3 weeks after onset showed marked limitation of left eye movements except for abduction with a 25 diopter left hypertropia and 25 diopter exotropia. The left lid was moderately ptotic. Pupillary examination was normal as were other findings. MRI and MR angiography were normal. He began to enjoy progressive improvement starting 5 weeks after onset and continuing for the next 2 months. Re-examination 4 months after onset showed complete resolution.

\section{DISCUSSION}

These three patients experienced sudden onset of diplopia during extreme emotional stress. Each was found to have an isolated cranial ocular motor nerve palsy, consisting of an otherwise complete but pupil-sparing 3rd nerve palsy in one patient and a 6th nerve palsy 
in two. Neuro-imaging studies and ancillary testing were negative in each, and all three experienced complete recovery over the next 3 months. Clinical features in all were consistent with a vasculopathic ocular motor nerve palsy.

The occurrence of cardiovascular and cerebrovascular events following stress has been previously documented. For example, Tsuchida et al found a significant increase in the incidence of acute coronary syndrome and cerebral hemorrhage during the 7 days following severe earthquake in a rural area of Japan (Tuschida et al., 2009). There are a number of mechanisms by which such severe emotional stress might produce an ischemic cranial mononeuropathy. Such emotional states may be associated with dramatic sympathetic over activity, characterized by markedly elevated levels of plasma catecholamines and stress-related neuropeptides (Wittstein et al., 2005). These stress-induced autonomic changes have been shown to cause coronary vasoconstriction in normal subjects (Lacy et al., 1995) and in patients with transient left ventricular dysfunction (Bybee et al., 2004). Similar vasospasm might affect the intra-cranial vessels that supply the ocular motor nerves, precipitating ischemic demyelination and producing an acute cranial nerve palsy. Alternatively, the autonomic changes accompanying stress in our patients may have caused acute myocardial dysfunction with secondary changes in intra-cranial hemodynamics. Acute reversible left ventricular dysfunction due to sudden emotional stress, termed "myocardial stunning," has been well documented although the mechanism in such cases is not fully understood (Wittstein et al., 2005). Coronary vasoconstriction, direct myocyte injury, and

\section{REFERENCES}

Asbury, A. K., Aldredge, H., Hershberg, R., and Fisher, C. M. (1970). Oculomotor palsy in diabetes mellitus: a clinicalpathologic study. Brain 93, 555-566.

Bybee, K. A., Prasad, A., Barsness, G. W., Lerman, A., Jaffe, A. S., Murphy, J. G., Wright, R. S., and Rihal, C. S. (2004). Clinical characteristics and thrombolysis in myocardial infarction frame counts in women with transient left ventricular apical ballooning syndrome. Am. J. Cardiol. 94, 343-346.

Cahill,M.,Bannigan,J., and Eustace,P.(1996). Anatomy of the extraneural blood supply to the intracranial oculomotor nerve. $\mathrm{Br}$. J. Ophthalmol. 80, 177-181.

Donahue, S., and Taylor, R. (1998). Pupilsparing third nerve palsy associated with sildenafil citrate (Viagra). Am. J. Ophthalmol. 126, 476-477. Layde, P. M. (1994). Risk factors for ischemic ocular motor palsies. Arch. Ophthalmol. 112, 961-966.

Lacy, C. R., Contrada, R. J., Robbins, M. L., Tannenbaum, A. K., Moreyra, A. E., Chelton, S., and Kostis, J. B. (1995). Coronary vasoconstriction induced by mental stress (simulated publicspeaking). Am. J. Cardiol. 75, 503-505.

Lapresle, J., and Lasjaunias, P. (1986). Cranial nerve ischemic arterial syndromes: a review. Brain 109, 207-216.

Richards, B. W., Jones, F. R., and Younge, B. R. (1992). Causes and prognosis in 4,278 cases of paralysis of the oculomotor, trochlear, and abducens cranial nerves. Am. J. Ophthalmol. 113, 489-496.

Tuschida, M., Kawashiri, M. A., Teramoto, R., Takata, M., Sakata, K., Omi, W., Okajima, M., Takamura, M., Ino H.,
Jacobson, D. M., McCanna, T. D., and

cardiac arrhythmia may play a role. A decrease in cardiac output, even if transient, could cause a drop in perfusion pressure within the watershed area of the cranial nerves and could thus lead to an ischemic cranial neuropathy. The possible role of transient systemic hypotension in the pathogenesis of vasculopathic ocular motor palsies has not been established, however the excellent prognosis for complete recovery and the absence of pathologic evidence of vascular occlusion in such cases would be compatible with such a mechanism. Such transient systemic hypotension was proposed as the mechanism in one reported case of pupil-sparing 3rd nerve palsy associated with the use of sildenafil citrate (Viagra) (Donahue and Taylor, 1998).

Certainly emotional stress is an uncommon cause for vasculopathic cranial nerve palsy. For example, during the time period in which these three patients were seen, we examined 112 and 91 cases of vasculopathic 6th and 3rd nerve palsy, respectively in which stress was not an apparent factor. One reason to draw the attention of the clinician to this unusual event is that the occurrence of a neurologic deficit in the setting of emotional stress may suggest the possibility of a functional disorder, i.e., a conversion reaction. As these cases illustrate, severe stress may also precipitate organic neurologic disease in some individuals. Stress is a well-recognized precipitant of migraine and has been investigated as a possible trigger factor for some exacerbations of multiple sclerosis. These cases are also of interest because the role of stress in the pathogenesis of other neurologic disorders has not been fully explored.

Kita Y., Takegoshi, T., Inaba, H., and Yamagishi, M. (2009). Impact of severe earthquake on the occurrence of acute coronary syndrome and stroke in a rural area of Japan. Circ. J. 73, 1243-1247.

Weber, R. B., Daroff, R. B., and Mackey, E. A. (1970). Pathology of oculomotor nerve palsy in diabetics. Neurology 20, 835-838.

Wittstein, I. S., Thiemann, D. R., Lima, J., Baughman, K. L., Schulman, S. P., Gerstenblith, G., Wu, K. C., Rade, J. J., Bivalacqua, T. J., and Champion, H. C. (2005). Neurohumoral features of myocardial stunning due to sudden emotional stress. N. Eng. J. Med. 352, 539-548.

Conflict of Interest Statement: The author declares that the research was conducted in the absence of any commercial or financial relationships that could be construed as a potential conflict of interest.

Received: 14 September 2010; paper pending published: 29 September 2010; accepted: 25 October 2010; published online: 18 November 2010.

Citation: Purvin V (2010) Vasculopathic cranial ocular motor neuropathy following sudden emotional stress. Front. Neur. 1:145. doi: 10.3389/fneur.2010.00145

This article was submitted to Frontiers in Neuro-ophthalmology, a specialty of Frontiers in Neurology.

Copyright $(2010$ Purvin. This is an openaccess article subject to an exclusive license agreement between the authors and the Frontiers Research Foundation, which permits unrestricted use, distribution, and reproduction in any medium, provided the original authors and source are credited. 